\title{
New varieties of Magnolia biondii and Magnolia cylindrica (Magnoliaceae) in China
}

\author{
Y.L. Wang ${ }^{1,2}$, E. Ejder ${ }^{3}$, J.F. Yang ${ }^{1}$, Y.X. Kang ${ }^{4}$, W. Ye ${ }^{5}$, S.Z. Zhang ${ }^{1}$
}

Key words

China

Magnolia

Magnolia biondii

Magnolia cylindrica

Magnoliaceae

tetraploid

variety

\begin{abstract}
Magnolia biondii var. purpurascens var. nov. and Magnolia cylindrica var. purpurascens var. nov. (Magnoliaceae) are described as two new varieties endemic to China. Magnolia biondii var. purpurascens is mainly restricted to forests of Shaanxi and SE Gansu provinces. It differs from the typical variety, M. biondii var. biondii, in the dense indumentum of white hairs on twigs and the cup-shaped purplish red flowers. Magnolia cylindrica var. purpurascens occurs in secondary forests of Jingning and Songyang counties of southern Zhejiang province. It differs from the typical variety, M. cylindrica var. cylindrica, in the cup-shaped flowers of purplish red colour. The two new varieties are distinct in their distributions in both cases but share the chromosome numbers with their typical varieties. Magnolia biondii var. purpurascens is a diploid with $2 n=38$, whereas $M$. cylindrica var. purpurascens is a tetraploid with $2 \mathrm{n}=76$.
\end{abstract}

Published on 17 June 2013

\section{INTRODUCTION}

Magnolia subg. Yulania (Spach) Rchb. comprises of about 16 species, mainly distributed in temperate and subtropical regions of East Asia and North America (Liu \& Wu 1996). However, the majority of these species are native to the mountainous regions of east and west China. Several species are cultivated as ornamental flowering trees in gardens as they have highly attractive flowers in spring. For many years we have investigated wild localities of this subgenus of Magnolia, especially in central and southern China. In this study, two new varieties of Magnolia are described and illustrated. Liu's taxonomic system is used in this article (Liu \& Wu 1996). Chromosome counts were made by protocols previously described (Wang et al. 2005).

\section{Magnolia biondii Pamp. var. purpurascens Y.L.Wang \& \\ S.Z.Zhang, var. nov. - Fig.1, 2; Map 1}

A varietate typica differt surculis et foliis subtus dense albo-pilosis, corollis cupulatis, tepalis late obovatis fere omnibus extus a basi ad medium vel ad apicem purpurascentibus. - Typus: Y.L. Wang Y20080308 (holo SZG), China, Shaanxi province, Lueyang county, Mount Qinling, in deciduous forest along a stream at the bottom of a valley, alt. $1018 \mathrm{~m}, \mathrm{~N} 33^{\circ} 31^{\prime} 40^{\prime \prime}$, E10609'37", 8 Mar. 2008.

Deciduous trees to $18 \mathrm{~m}$ tall. Bark pale grey, smooth; one or two years old twigs green, usually $3-4 \mathrm{~mm}$ diam, densely pale yellow to white appressed-pubescent. Petiole 1-2 cm, stipular scar $1 / 5-1 / 3$ as long as the petiole; leaf blades narrowly elliptic, narrowly ovate or narrowly obovate, $10-18$ by $3-5 \mathrm{~cm}$, beneath light green, at first lanate-pubescent, above dark green; base cuneate, apex acute to shortly acuminate. Peduncle c. $1 \mathrm{~cm}$; flower buds erect with pale greyish brown hair, spathe

\footnotetext{
Fairylake Botanical Garden, Shenzhen \& Chinese Academy of Sciences, Shenzhen 518004, China;

corresponding author e-mail: shouzhouz@yahoo.com.cn.

2 Qinling National Botanical Garden, Xi'an 710061, China.

3 Swedish Magnolia Group, Laholm, Sweden.

${ }^{4}$ College of Forestry, Northwest Agriculture and Forestry University, Yangling 712100, China.

5 Xi'an Botanical Garden, Xi'an 710061, China.
}

2-7; flowers cup-shaped, precocious, light fragrance, 5-7 cm diam; tepals 9 , outer 3 tepals sepaloid, purplish red or light red, linguoid, $1-1.5 \mathrm{~cm}$ long; tepals of middle and inner whorls abaxially purplish red or purplish red from base to middle, petal-like, obovate-oblong, $3.7-5$ by $1.8-3 \mathrm{~cm}$, erect; stamens $8-10 \mathrm{~mm}$ long, filaments purple 3-4 mm, anthers $4-5 \mathrm{~mm}$; gynoecium $2 \mathrm{~cm}$ long. Fruiting peduncle 1 by $0.7 \mathrm{~cm}$, with residual long sericeous hairs; fruit cylindrical, $10-14 \mathrm{~cm}$ long, mature follicles red, suborbicular, compressed laterally, tuberculate; red aril and black seeds with deep furrow. Chromosome number: $2 n=2 x=38$.

Distribution \& Habitat - Distributed in SE Gansu province (Huixian county), in S Shaanxi province (Foping, Langao, Lueyang, Ningshan, Pingli, Xunyang counties); in deciduous forests at $520-1320 \mathrm{~m}$. Flowering: February to mid-March; fruiting: ripening August to September.

Accompanying vegetation - Acermono Maxim., Betula platyphylla Sukaczev, Broussonetia papyrifera (L.) L'Hér. ex Vent., Castanea mollissima Blume, Celastrus orbiculatus Thunb., Corylus heterophylla Fisch. ex Trautv., Cunninghamia lanceolata (Lamb.) Hook., Diospyros lotus L., Euptelea pleiospermum Hook.f. \& Thomson, Helwingia chinensis Batalin, H. japonica (Thunb.) F.Dietr., Juglans cathayensis Dode, Larix gmelini (Rupr.) Rupr., Lindera obutusiloba Blume, L. pungens Hemsl., Lonicera tangutica Maxim., Magnolia sprengeri Pamp., Pinus armandii Franch., P. tabuliformis Carrière, Populus adenopoda Maxim., Quercus aliena Blume var. acuteserrata Maxim. ex Wenz., Rhus chinensis Mill., Sabina chinensis (L.) Antoine, Tsuga chinensis (Franch.) Pritz., Vitis heyneana Roem. \& Schult.

Conservation - In the past, this species has suffered severely from large-scale forestry operations but the situation has recently improved as a result of the introduction of stringent forestry regulations. During fieldwork, we encountered only very small groups composed of $1-3$ but occasionally up to 10 individuals. They usually occurred along streams at the bottom of valleys. Seed production can sometimes be abundant. Young seedlings were very rarely found and then in very low numbers. The flower buds were used as medicinal Xinyi in these areas in the past. 


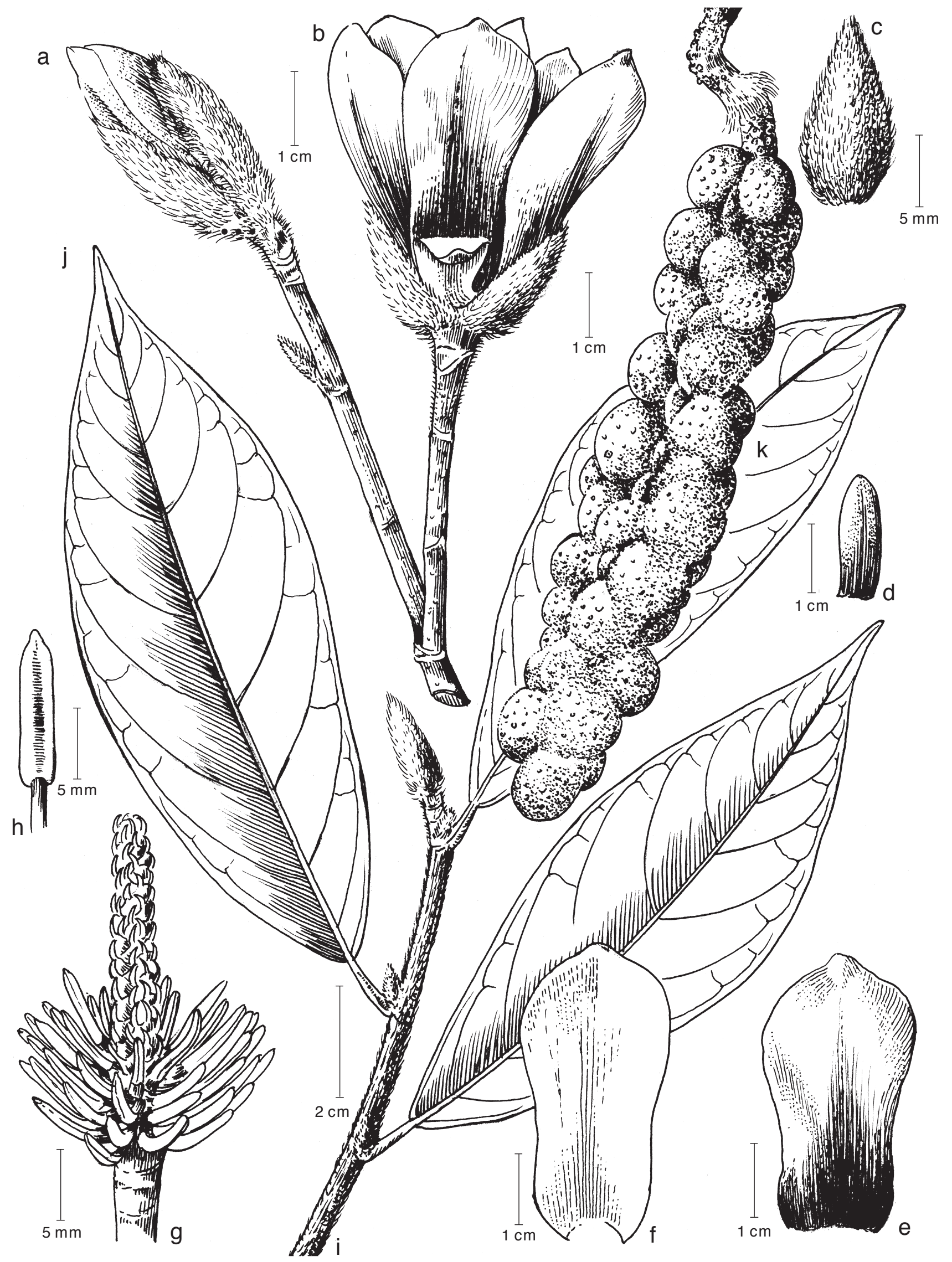

Fig.1 Magnolia biondii Pamp. var. purpurascens Y.L.Wang \& S.Z.Zhang. a. Flower bud; b. flower; c. bract; d. outer tepal; e. abaxial face of middle tepal; f. adaxial face of middle tepals; g. androecium and gynoecium; h. stamen; i. twig; j. leaf; k. fruit. — Drawn by Cui DH. 

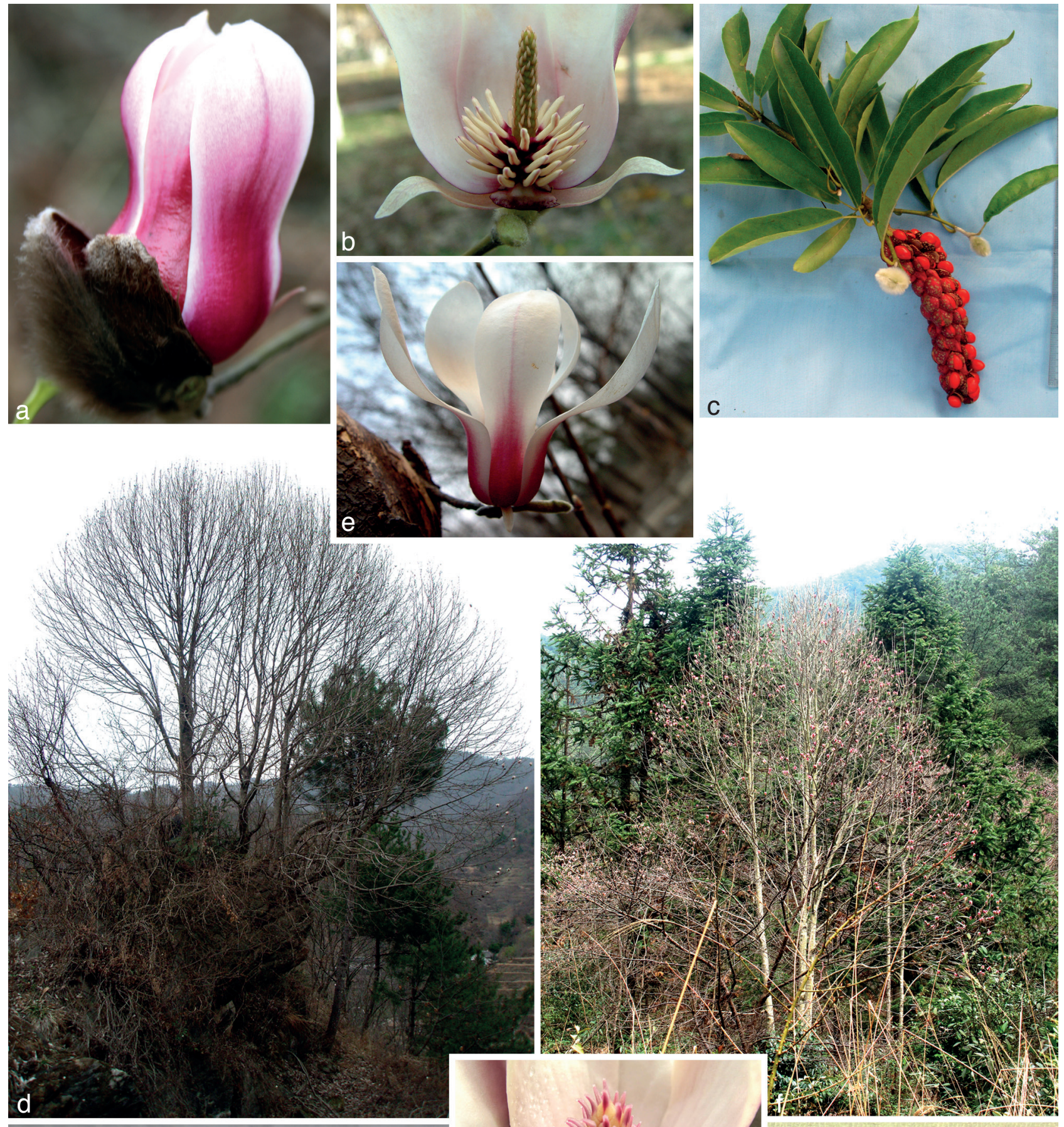

(1)

(n)

w $1(1)$

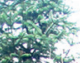
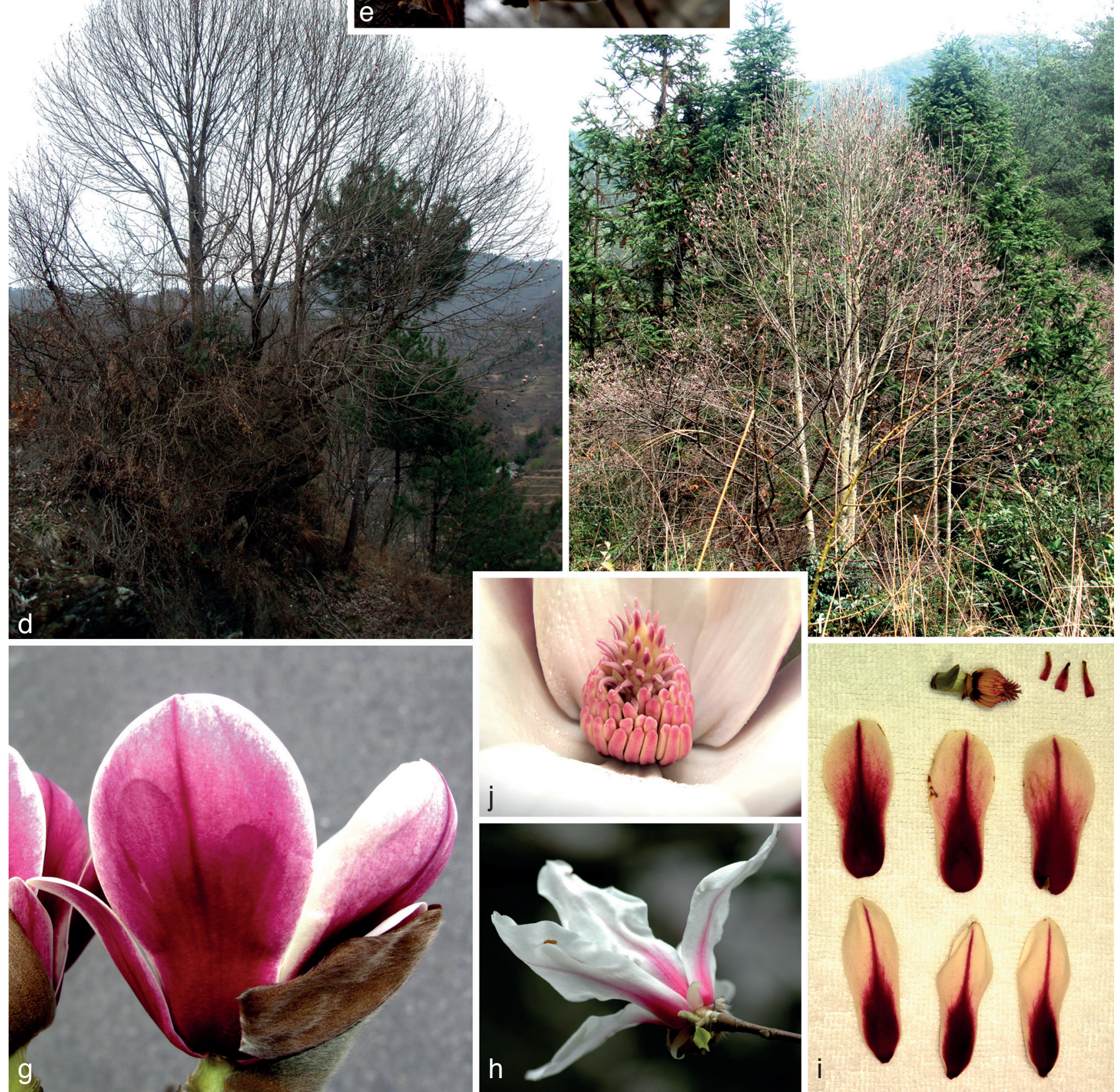

Fig. 2 Photos of the two species and their varieties. a-c, e. Magnolia biondii Pamp. var. purpurascens Y.L.Wang \& S.Z.Zhang in E Ningshan county of Shaanxi province; d. M. biondii Pamp. var. biondii from Henan; f-i. M. cylindrica E.H.Wilson var. purpurascens Y.L.Wang \& S.Z.Zhang in Jingning county of Zhejiang province; j. M. cylindrica E.H.Wilson var. cylindrica in Huangshan Mt of Anhui province. 


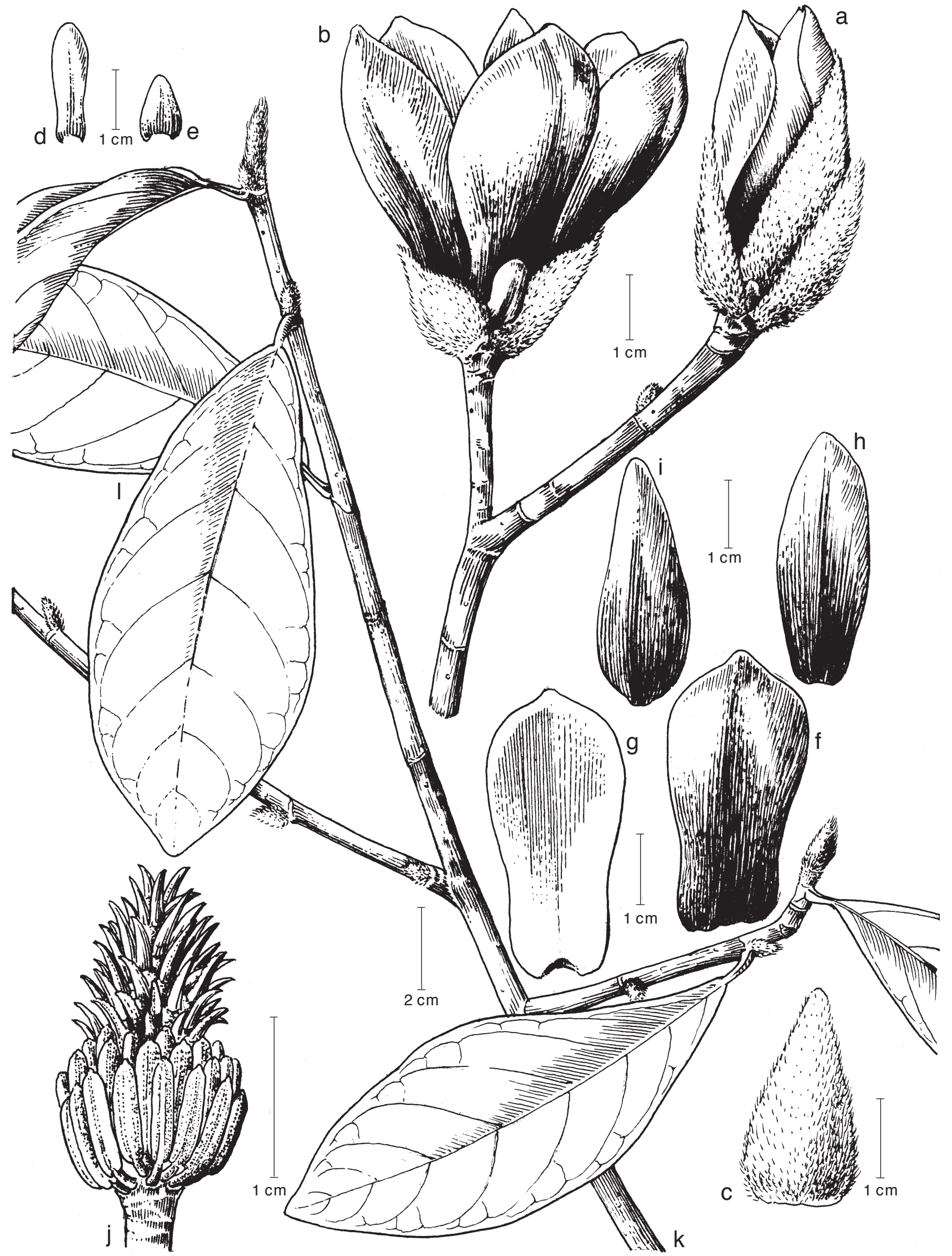

Fig. 3 Magnolia cylindrica E.H.Wilson var. purpurascens Y.L.Wang \& S.Z.Zhang. a. Flower bud; b. flower; c. bract; d, e. outer tepals; f. abaxial face of middle tepal; g. adaxial face of middle tepals; $h$, i. abaxial face of inner tepals; j. androecium and gynoecium; k. twig; I. leaf. — Drawn by Cui DH. 


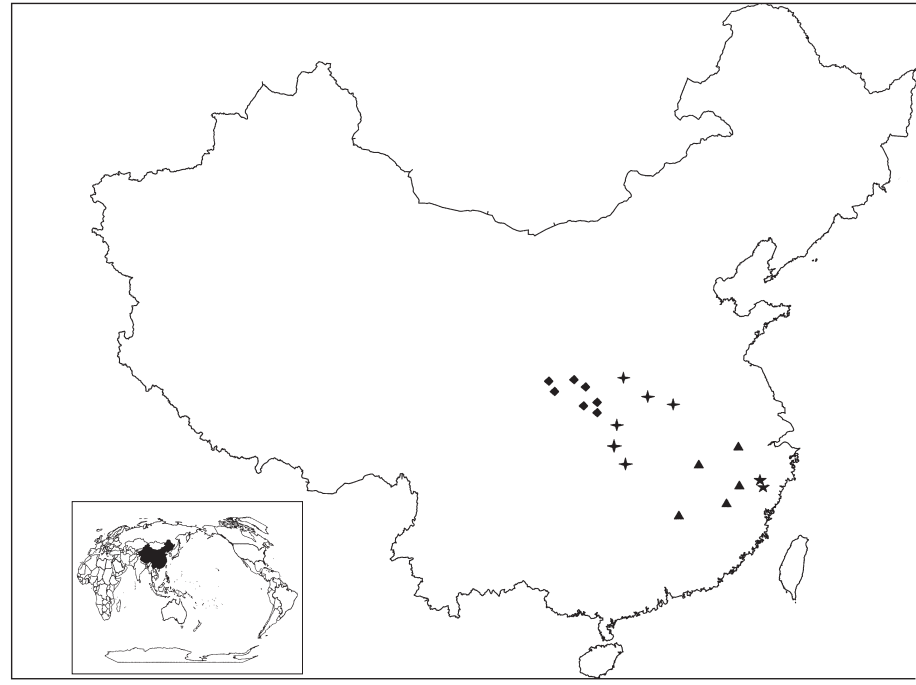

Additional specimens. CHINA, Shaanxi, Lueyang, alt.1018 m, N33³1'40", E10609'37", 9 Aug. 2006, Y.L. Wang, Y20060809 (fruits) (SZG); Shaanxi, Xunyang, alt. $520 \mathrm{~m}, \mathrm{~N} 33^{\circ} 08^{\prime}, \mathrm{E} 109^{\circ} 03^{\prime}, 16$ Mar. 2007, Y.L. Wang, Y20070316 (flowers) (SZB); Shaanxi, Foping, alt. 1184-1316 m, N33 ${ }^{\circ} 33^{\prime}-33^{\circ} 35^{\prime}$, E107²6'-10750', 25 Apr. 2010, Y.L. Wang Y20100425-1, Y20100425-4, Y20100425-6 (fruits) (SZG); Gansu, Huixian, Xiaolongshan National Natural Reserve, alt. $1057 \mathrm{~m}, \mathrm{~N} 33^{\circ} 40^{\prime}, \mathrm{E} 106^{\circ} 19^{\prime}, 27$ Apr. 2010; Y.L. Wang, Y20100427-1, Y20100427-2 (fruits) (SZG)

Additional observations. CHINA, Shaanxi, Langao, alt. 1022-1092 m, N32 ${ }^{\circ} 18^{\prime}-32^{\circ} 19^{\prime}, \mathrm{E} 109^{\circ} 02^{\prime}$; Shaanxi, Pingli, alt. $739 \mathrm{~m}, \mathrm{~N} 32^{\circ} 18^{\prime}, \mathrm{E} 109^{\circ} 28^{\prime}$; Shaanxi, Ningshan, alt. $1092-1310$ m, N33 ${ }^{\circ} 18^{\prime}-33^{\circ} 19^{\prime}$, E108 $26^{\prime}-108^{\circ} 29^{\prime}$.

Notes - The new variety shows a distribution distinct from M. biondii var. biondii which occurs in Chongqing, W Henan, W Hubei and N Hunan (Liu et al. 2004, Xia et al. 2008). The flowers of var. biondii are usually white with a pale or purplish red nerve or a pale red stain on the base of the tepals which reflex gradually as in Fig. $2 \mathrm{~d}$ which shows a medium open flower. The reflexing continues and eventually the tepals hang down before falling off in contrast to var. purpurascens where the purplepigmented tepals are held erect until they are shed. Previous studies recorded this variety as diploid (Chen et al.1985, Li et al. 1998).

We have investigated many localities of $M$. biondii var. biondii, covering most its distribution area including the Xinyang, Nanzhao and Lushi counties in Henan province, Mount Shennongjia and Wufeng county in Hubei province, Cili county in Hunan province. All the trees observed in those localities show flower morphology consistent with that of var. biondii. The specimens from southern Shaanxi and Gansu, here described as the new var. purpurascens, are different, having flowers with erect and broadly obovate tepals of dark red colour abaxially. While $M$. biondii var. biondii often produce abundant but rather insignificant flowers, the new variety here described, $M$. biondii var. purpurascens, is an attractive garden tree for its shape and its purple or purple and white flowers.

\section{Magnolia cylindrica E.H.Wilson var. purpurascens Y.L.Wang} \& S.Z.Zhang, var. nov. - Fig. 2, 3; Map 1

A varietate typica differt corollis cupulatis, tepalis late obovatis fere omnibus extus a basi ad medium vel ad apicem purpurascentibus. - Typus: Y.L. Wang Y2010-15 (holo SZG), China, Zhejiang province, Jingning county, deciduous forest, alt. $1215 \mathrm{~m}, \mathrm{~N} 27^{\circ} 44^{\prime}, \mathrm{E} 119^{\circ} 38^{\prime}, 27$ Feb. 2010.

Deciduous trees to 8-12 m tall. Bark pale grey, smooth; twigs yellowish brown. Petiole $1.2-1.8 \mathrm{~cm}$, stipular scars $1 / 5-1 / 3$ as long as petiole; leaf blades narrowly obovate or obovate-oblong, $14-17$ by $7-8 \mathrm{~cm}$, papery, green above, light green beneath with densely short hairs, base broadly cuneate, apex obtuse or acute. Peduncle 0.9-1.1 cm, densely pale yellow sericeous; flower buds ovoid, with pale greyish yellow to silvery grey long hairs; flowers cup-shaped, precocious; tepals 9, outer 3 tepals sepaloid, triangular or linguoid, $0.8-3$ by $0.5-0.9 \mathrm{~cm}$; tepals of middle and inner whorls purplish red abaxially but sometimes more or less white at the apex, petal-like, obovate-oblong, $3.7-4.2$ by $1.8-2.2 \mathrm{~cm}$, erect; stamens $0.8-1.0 \mathrm{~cm}$, filament base purplish red, connective exerted and forming a tip or mucro; gynoecium purplish yellow, cylindrical-ovoid, 1.2-1.5 $\mathrm{cm}$ long, 50-65 carpels. Chromosome number $2 n=4 x=76$ according to count in leaf bud samples.

Distribution \& Habitat - Endemic to Jingning and Songyang County, South of Zhejiang Province, China, in the semievergreen broad-leaved forests at $1100-1220 \mathrm{~m}$. The area of occurrence belongs to the oceanic monsoon climate of the subtropical climatic zone. The Jingning population comprised 10 trees of which 7 were sampled for flowers and dry leaves. More than 20 trees were observed in Songyang county and 4 were sampled for flowers and dry leaves. No fruits were found in either area. The flower shape and other morphological characters are very homogeneous in and between the two populations. The abaxial tepal colour shows some variation in the extension of the white margin at the apex. No young seedlings were found around those trees. The populations are distributed within conservation areas of a local forest bureau and plants are protected very well in both areas. Some individuals of $M$. cylindrica var. purpurascens grow on the slope of a valley, whereas others were found along brooklets. Flowering: from the end of February to middle March; Fruiting: unseen.

Accompanying vegetation - Alnus trabeculosa Hand.-Mazz., Bretschneidera sinensis Hemsl., Camellia chekiangoleosa Hu, Chimonobambusa quadrangularis (Franceschi) Makino, Emmenopterys henryi Oliv., Halesia macgregorii Chun, Pinus taiwanensis Hayata, Taxus wallichiana var. mairei (Lemée \& H.Lév.) L.K.Fu \& Nan Li. There is also a larger population of Magnolia sinostellata P.L.Chiu \& Z.H.Chen growing together with this variety in the Songyang population, but no $M$. sinostellata individual was observed in the Jingning population.

Additional specimens. CHINA, Zhejiang province, Jingning, alt. 900-1100 m, N27²4', E119 $38^{\circ}, 27$ Feb. 2010, Y.L. Wang, Y2010-16, Y2010-17, Y201018; Zhejiang province, Songyang, alt. 880-1000 m, N28 ${ }^{\circ} 16^{\prime}, \mathrm{E} 119^{\circ} 32^{\prime}$, 26 Mar. 2012, Y.L. Wang, Y20120326-01, Y20120326-02, Y20120326-04, Y20120326-08.

Notes - The new variety is distinct in its separate distribution compared with M. cylindrica var. cylindrica, which is found in the montane sparse forest at an altitude of 600-1700 in S Anhui, Zhejiang, Jiangxi and N Fujian (Liu et al. 2004, Xia et al. 2008). 
The majority of known localities of var. cylindrica were investigated in the past years including Mount Huangshan in Anhui province, Mount Wuyi and Mount Efeng in Fujian province, Mount Lushan and Jinggang in Jiangxi province. The flowers of the typical variety are usually white with a purplish red nerve abaxially on the base. The tepals reflex as the flower develops as in Fig. 2j which shows an open flower. The tepals will keep reflexing further until they hang down and eventually fall off. These floral characters, which were common to all individuals observed in those localities of $M$. cylindrica var. cylindrica, differ from the erect purple-pigmented flowers of $M$. cylindrica var. purpurascens of S Zhejiang. The var. purpurascens is tetraploid (like var. cylindrica) in our chromosome counts.

This variety is an attractive garden tree based on its nice treeshape and purplish red flower. The flower buds or tree bark are not used as medicinal Xinyi or Houpu in these areas.

\section{Etymology}

It is a coincidence that in the two different species studied, Magnolia biondii and M. cylindrica flowers of similar shape and colour occur and are described here with the same epithet, purpurascens, for both new varieties.

\section{Some comments on wild material}

The flower buds of most deciduous Magnolias are traditional sources of the Chinese herbal medicine Xinyi. Sometimes wild growing trees were felled to harvest flower buds. The market demand for these products has decreased in recent years and the pressure on remaining wild Magnolia populations has eased. Buds of $M$. biondii are among the typical sources of Xinyi and the usage has had a strong impact on wild populations of this species. However, the use in Xinyi motivated the planting of $M$. biondii trees at mountain farms for domestic or small commercial flower-bud harvesting. These farms are usually found in Henan and Hubei provinces. Material from cultivated specimens has not been included in our investigation.
Acknowledgements The study was supported by the National Natura Science Foundation of China (grant number 30970180) and the National Spark Program of China (grant number 2010GA780012). Many thanks to Dr. KE Flinck for the generous financial support and his interest in the study. The authors are grateful to Yuan-Ke Xu, Li-Min Ye, Rao Liu and other colleagues from Jingning Forestry Bureau, the staff from Caoyutang Forestry Farm and Wangdongyang Forestry Farm, Liang Liao and Yuan-Rong Li from Yangdangshan Forestry Bureau, Zhang-Gui Gao and Li-Fang Que from Songyang Forestry Bureau, Yu-Chao Chen and Zhi-Hu Ma from Ankang prefecture Forestry Bureau, Ning-Chao Tian from Ningshan Forestry Bureau, Zheng-Ping Liao from Langao Forestry Bureau for their generous assistance and cooperation. Many thanks to Mei Yang, Wei Ye, Ya-Mei Shen and Jun-Juan Li for contributing to the field work. Thanks are due to Zi-Can He for the chromosome studies.

\section{REFERENCES}

Chen RY, Chen ZG, Li XL, Song WQ. 1985. Chromosome numbers of some species in the family Magnoliaceae in China. Acta Phytotaxonomica Sinica 23: 103-105.

Li XL, Song WQ, An ZP, Chen RY. 1998. Karyotype analysis of some species of Magnoliaceae in China. Acta Botanica Yunnanica 20: 204-206.

Liu YH, Wu RF. 1996. Magnoliaceae. In: Liu YH, Wu RF, Flora Reipublicae Popularis Sinicae, Tomus. 31, 1: 82-273. Science Press, China. [In Chinese.]

Liu YH, Zeng QW, Zhou RZ, Xing FW. 2004. Magnolias of China. Beijing Science and Technology Press, China.

Xia NH, Liu YH, Nooteboom HP. 2008. Magnoliaceae. In: Wu ZY, Flora of China, vol. 7: 47-91. Missouri Botanical Garden Press, St. Louis and Science Press, Beijing

Wang YL, Zhang SZ, Li Y, Zhang WH. 2005. Chromosome numbers of 13 taxa and 12 crossing combinations in Magnoliaceae. Acta Phytotaxonomica Sinica 43: 545-551. 